• 研究报告・

\title{
广州南沙十四涌潮间带大型底栖动物的功能群
}

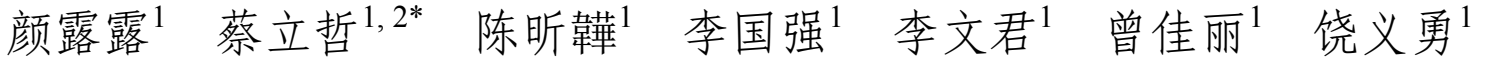 \\ 1 (厦门大学环境与生态学院, 福建厦门 361102) \\ 2 (厦门大学滨海湿地生态系统教育部重点实验室, 福建厦门 361102)
}

\begin{abstract}
摘要: 大型底栖动物根据食性可分为浮游生物食者(planktophagous, Pl)、植食者(phytophagous, Ph)、肉食者 (carnivorous, C)、杂食者(omnivorous，O)和碎屑食者(detritivorous，D)五个功能群。本文根据2007-2008年度和 2013-2014年度在茫芏(Cyperus malaccensis)、海桑(Sonneratia caseolaris)2种生境调查获得的各4个季度的大型底栖 动物数据, 分析了广州南沙十四涌潮间带大型底栖动物功能群的生境差异、季节变化和年际变化。2007-2008年度 采集到26种大型底栖动物, 低于2013-2014年度的36种。无论是2007-2008年度还是2013-2014年度, 茫芏、海桑生 境的大型底栖动物均以植食者的栖息密度和生物量最高, 碎屑食者的栖息密度和生物量最低。生境比较得出, 茳 芏生境大型底栖动物浮游生物食者 $(\mathrm{Pl})$ 的丰富度指数 $(d)$ 、均匀度指数 $(J)$ 和多样性指数 $(H)$ 均高于海桑生境。年度 比较得出, 在茫芏和海桑生境, 2013-2014年度浮游生物食者的丰富度指数、均匀度指数和多样性指数均高于 2007-2008年度, 这是因为2013-2014年度采集到红树蚬(Gelonia coaxans)和彩虹明樱蛤(Morerlla iridescens)等, 而 2007-2008年度没有采集到。
\end{abstract}

关键词: 大型底栖动物; 功能群; 生境; 潮间带; 十四涌

\section{Functional groups of benthic macrofauna in the 14th Yong intertidal zone of Nansha, Guangzhou}

\author{
Lulu Yan ${ }^{1}$, Lizhe Cai ${ }^{1,2^{*}}$, Xinwei Chen ${ }^{1}$, Guoqiang $\mathrm{Li}^{1}$, Wenjun $\mathrm{Li}^{1}$, Jiali Zeng ${ }^{1}$, Yiyong Rao ${ }^{1}$ \\ 1 College of the Environment and Ecology, Xiamen University, Xiamen, Fujian 361102 \\ 2 Key Laboratory of the Ministry of Education for Coastal and Wetland Ecosystems, Xiamen University, Xiamen, Fujian \\ 361102
}

\begin{abstract}
Benthic macrofauna were classified into 5 functional groups, i.e. planktophagous (Pl), phytophagous $(\mathrm{Ph})$, carnivorous $(\mathrm{C})$, omnivorous $(\mathrm{O})$ and detritivorous $(\mathrm{D})$. The biotope difference, seasonal and annual variations of functional group of benthic macrofauna in the intertidal zone of the 14th Yong of Nansha, Guangzhou were analyzed in this study according to the four seasonal data of benthic macrofauna collected in two biotopes (Cyperus malaccensis and Sonneratia caseolaris) in 2007-2008 and 2013-2014. A total of 26 species were recorded in 2007-2008, which was lower than 36 species in 2013-2014. Both in 2007-2008 and 2013-2014, phytophagous group showed the highest value while detritivorous group shared the lowest one in density and biomass. Habitat comparison showed that the abundance index $(d)$, evenness index $(J)$ and diversity index $\left(H^{\prime}\right)$ of planktophagous group in Cyperus malaccensis habitat were all higher than those in Sonneratia caseolaris habitat. Annual comparison showed that the abundance index, evenness index and diversity index of planktophagous group in 2013-2014 were all higher than those in 2007-2008 both in Cyperus malaccensis and Sonneratia caseolaris habitats because the planktophagous such as Gelonia coaxans and Morerlla iridescens and so on were collected in 2013-2014 but they were not found in 2007-2008.
\end{abstract}

Key words: benthic macrofauna; functional group; habitat; intertidal zone; the 14th Yong

收稿日期: 2016-02-04; 接受日期: 2016-03-08

基金项目: 国家自然科学基金(41176089 和 41376113)

* 通讯作者 Author for correspondence. E-mail: cailizhe@xmu.edu.cn 
功能群指具有共同功能特征或利用相同资源 的类群(同源群), 应用在生态学研究中可简化群落 内物种之间的关系。功能群对环境变化的响应弱化 了物种的个别作用, 比个体及种群的反应更重要、 综合性更强(辛俊宏等, 2011)。潮间带生态系统由于 处于海陆过渡地带, 海陆理化因子交替作用, 物质 交换过程复杂多变, 其中潮间带的大型底栖动物由 于其在食物网(链)中的重要作用, 一直倍受关注(葛 宝明等, 2008)。

国内学者对潮间带大型底栖动物功能群的研 究区域主要集中在浙江以北潮间带(袁兴中等, 2002; 朱晓君和陆健健, 2003, 李欢欢等, 2007; 魏 德重等, 2012), 以及福建泉州湾蟳埔潮间带(李想 等, 2014)和深圳湾潮间带(蔡立哲, 2015)。在广州以 南沿海, 仅有黄睿婧等(2010)和刘莎等(2010)分别 报道了广州南沙十四涌、十九涌潮间带的大型底栖 动物群落, 廖宝文等(2013)综述了广州南沙湿地大 型底栖动物监测结果。但迄今为止, 在广州南沙湿 地尚未见大型底栖动物功能群的报道。

本文拟探讨广州南沙十四涌潮间带大型底栖 动物功能群在不同生境、季节和年度的分布, 为潮 间带大型底栖动物生态学研究和广州南沙湿地保 护提供基础资料。

\section{1 研究区域概况}

广州南沙十四涌潮间带地处广州市南沙区新
艮镇, 南濒珠江出海口伶仃洋。属南亚热带海洋性 季风气候, 潮汐为不正规半日潮, 海水盐度很低, 几乎接近淡水, 底质表层水的盐度范围在0-7 ppt。 该地区气候温暖, 年均气温 $21.9^{\circ} \mathrm{C}$, 最冷月平均气 温 $13.3^{\circ} \mathrm{C}, 7$ 月平均气温 $29^{\circ} \mathrm{C}$ (常弘等, 2007)。

\section{2 研究方法}

\section{1 样品采集与处理}

2007-2008年度大型底栖动物采用2007年2月 和 8 月、2008年5月和 11 月(分别代表冬季、夏季、春 季和秋季) 在茫芏 (Cyperus malaccensis) 和海桑 (Sonneratia caseolaris)2种生境的数据；2013-2014 年度大型底栖动物采用2013年7月和10月、2014年1 月和4月(分别代表夏季、秋季、冬季和春季)在茫芏 和海桑 2 种生境(图1)的数据。每种生境随机设置 5 个 样方, 每个样方面积为 $25 \mathrm{~cm} \times 25 \mathrm{~cm}$, 采样深度 20-30 cm, 所采泥样用 $0.5 \mathrm{~mm}$ 孔径的篮网进行分 选。大型底栖动物的采集、保存、鉴定和称重按《海 洋监测规范》(GB17378-2007)和《海洋调查规范》 (GB/T12763-2007)中的有关规定执行。

\section{2 功能群的划分}

依据大型底栖动物食性, 并参照袁兴中等 (2002)、葛宝明等(2008), 将大型底栖动物划分为以 下5 个功能群:

(1)浮游生物食者(planktonphagous group, Pl): 依靠各种过滤器官滤取水体中微小的浮游生物, 包

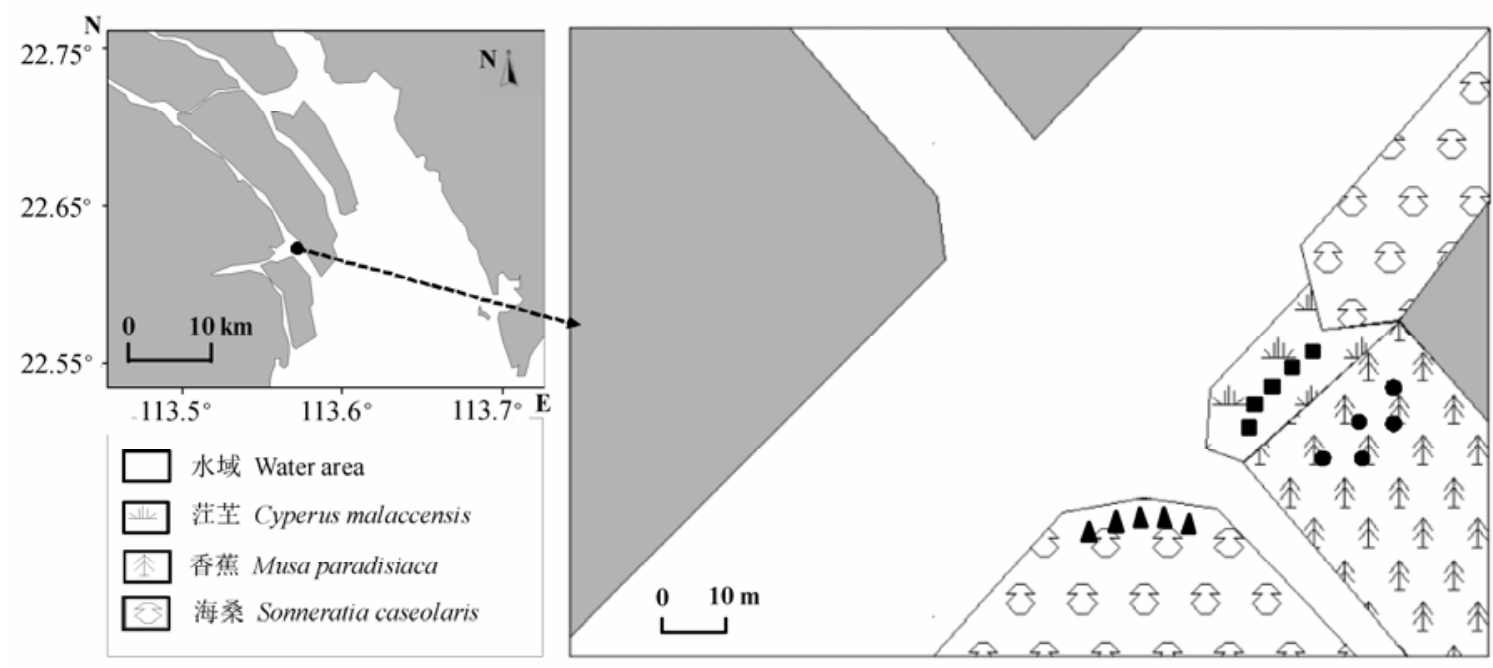

图1广州南沙十四涌潮间带大型底栖动物采样站位图

Fig. 1 Sampling sites of benthic macrofauna in the 14th Yong intertidal zone of Nansha, Guangzhou 
括藤壶、大部分双壳类和少数腹足类。

(2)肉食者(carnivorous group, C): 捕食小型动 物和动物幼体，如某些环节动物、十足类等。

(3)杂食者(omnivorous group, O): 依靠皮肤或 鳃的表皮, 直接吸收溶解在水中的有机物, 也可取 食植物腐叶和小型双壳类、甲壳类, 如某些腹足纲、 双壳纲和蟹类等。

(4)碎屑食者(detritivorous group, D): 摄食底表 的有机碎屑, 吞食沉积物, 在消化道内摄取其中的 有机物质，如某些线虫、双壳类等。

(5)植食者(phytophagous group, Ph): 主要以维 管束植物和海藻为饵料, 如某些腹足纲、双壳纲和 蟹类等。

\section{3 数据分析}

根据潮间带大型底栖动物群落的特点及取样 数据, 采用以下公式进行各功能群多样性分析(马 克平, 1994):

Margalef种类丰富度指数: $d=(S-1) / \log _{2} N$

Shannon-Wiener多样性指数: $H^{\prime}=-\sum P_{i} \log _{2} P_{i}$

Pielou均匀度指数 $J=H^{\prime} / H_{\max }$ 式中, $S$ 为物种数, $N$ 为个体数, $P_{i}$ 为第 $i$ 个物种出现的 频率。

运用Primer 5.0软件计算各功能群的多样性指 数, 并采用SPSS 15.0对数据进行无重复双因素方 差分析。

\section{3 结果}

\section{1 大型底栖动物功能群物种组成}

2007-2008年度在两种生境共采集到大型底栖 动物 26 种, 其中浮游生物食者 $(\mathrm{Pl})$ 和植食者 $(\mathrm{Ph})$ 各 5 种，肉食者 $(\mathrm{C}) 6$ 种，杂食者 $(\mathrm{O}) 9$ 种，碎屑食者 $(\mathrm{D}) 1$ 种, 杂食者 $(\mathrm{O})$ 物种数最多, 碎屑食者 $(\mathrm{D})$ 物种数最 少(附录1)。茫芏和海桑生境除了碎屑食者(D)均为 1 种外, 其余4种食者均是茫芏生境多于海桑生境。从 季节变化看, 四个季节均是肉食者 $(\mathrm{C})$ 物种数最多, 碎屑食者 $(\mathrm{D})$ 物种数最少(图 $2 \mathrm{~A})$ 。

2013-2014年度在茫芏和海桑生境共采集到大 型底栖动物 36 种, 其中浮游生物食者 $(\mathrm{P} 1) 10$ 种, 植 食者 $(\mathrm{Ph}) 5$ 种，肉食者 $(\mathrm{C}) 9$ 种，杂食者 $(\mathrm{O}) 7$ 种，碎屑 食者(D)5种(附录1)。茳芏生境的浮游生物食者 $(\mathrm{Pl})$ 和肉食者 $(\mathrm{C})$ 多于海桑生境, 植食者 $(\mathrm{Ph})$ 、杂食者 $(\mathrm{O})$ 和碎屑食者 $(\mathrm{D})$ 少于海桑生境。从季节变化看, 四个
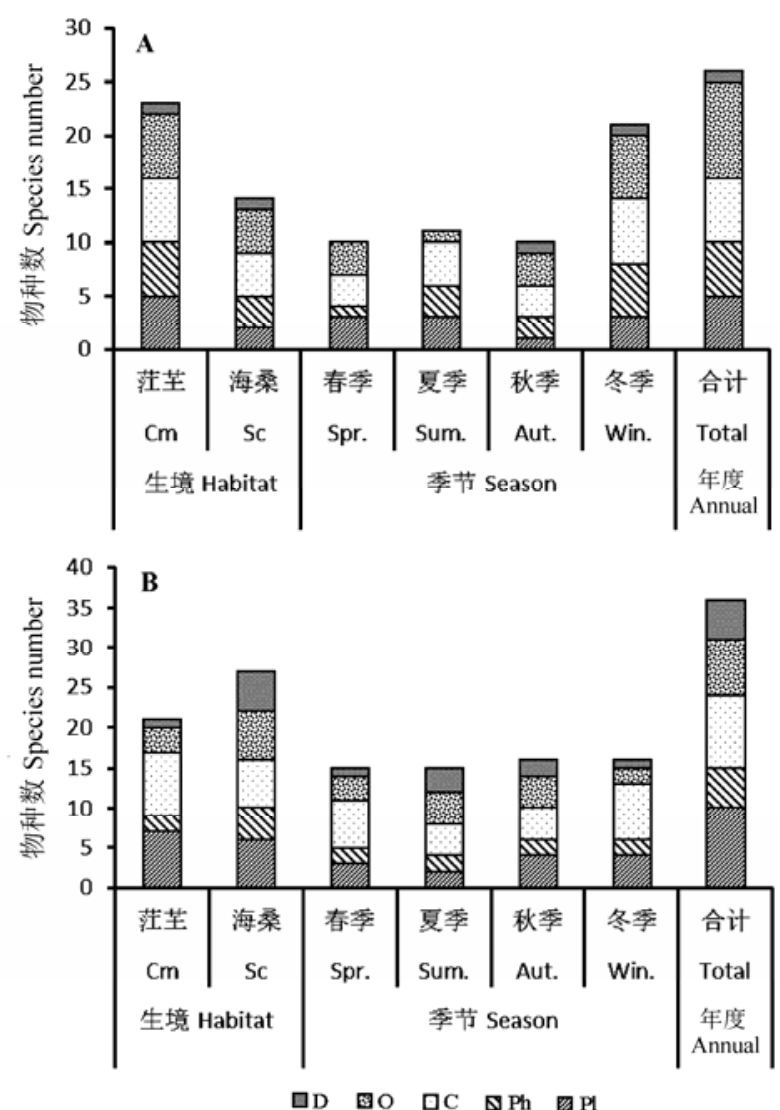

图2 2007-2008年度 $(\mathrm{A})$ 和 2013-2014年度(B)大型底栖动物 功能群物种组成。Cm: Cyperus malaccensis; Sc: Sonneratia caseolaris; Pl: 浮游生物食者; Ph: 植食者; C: 肉食者; O: 杂食者; D: 碎屑食者。

Fig. 2 Species composition of benthic macrofauna functional groups in 2007-2008 (A) and 2013-2014 (B). Cm: Cyperus malaccensis; Sc: Sonneratia caseolaris; P1: Planktonphagous; $\mathrm{Ph}$ : Phytophagous; C: Carnivorous; O: Omnivorous; D: Detritivorous.

季节均是肉食者 $(\mathrm{C})$ 物种数最多, 碎屑食者 $(\mathrm{D})$ 物种 数最少(图2B)。

2007-2008年度采集到的大型底栖动物(26种) 低于2013-2014年度(36种)。2个年度均是杂食者(O) 物种数最多, 碎屑食者 $(\mathrm{D})$ 物种数最少; 2 个年度四 个季节均是肉食者 $(\mathrm{C})$ 物种数最多, 碎屑食者 $(\mathrm{D})$ 物 种数最少。

\section{2 大型底栖动物功能群栖息密度组成}

2007-2008年度的大型底栖动物平均栖息密度 为 $2,061.2 \mathrm{ind} . / \mathrm{m}^{2}$, 茳芏生境略高于海桑生境, 冬季 明显高于其他季节。两种生境均是植食者 $(\mathrm{Ph})$ 占优 势, 分别占两种生境总栖息密度的 $54.45 \%$ 和 $67.32 \%$ 。碎屑食者(D)在两种生境中栖息密度很低， 
在茫芏生境和海桑生境分别仅占总栖息密度的 $0.01 \%$ 和 $0.09 \%$ 。碎屑食者 $(\mathrm{D})$ 在夏季和春季没有被 采集到(图3A)。

2013-2014年度大型底栖动物平均栖息密度为 1,527.2 ind. $/ \mathrm{m}^{2}$, 茫芏生境明显低于海桑生境, 四个 季节的大型底栖动物栖息密度差幅较小, 最大差幅 仅为 464.0 ind. $/ \mathrm{m}^{2}$ 。茫芏和海桑生境均以植食者 $(\mathrm{Ph})$ 的栖息密度最高, 分别占两种生境总栖息密度的 $35.02 \%$ 和 $32.05 \%$ 。肉食者 $(\mathrm{C})$ 在茳芏生境也占优势, 与植食者 $(\mathrm{Ph})$ 的栖息密度一样, 占总栖息密度的 $35.02 \%$ 。碎屑食者(D)在两种生境中栖息密度很低, 在茫芏和海桑生境分别占总栖息密度的 $1.15 \%$ 和 $2.93 \%$ 。杂食者 $(\mathrm{O})$ 栖息密度在夏、秋季占优, 其分 别占夏季总栖息密度的 $33.20 \%$ 和秋季的 $35.26 \%$ 。而 在冬季和春季栖息密度占优势的是植食者 $(\mathrm{Ph})$, 其 分别占总栖息密度的 $45.54 \%$ 和 $29.41 \%$ 。四个季度栖 息密度最低的均为碎屑食者(D), 其平均栖息密度 只有 $48.8 \mathrm{ind} . \mathrm{m}^{2}$, 仅占总栖息密度的 $3.20 \%$ (图3B)。

2007-2008年度的大型底栖动物栖息密度 $\left(2,061.6 \mathrm{ind} . / \mathrm{m}^{2}\right)$ 高于 $2013-2014$ 年度 $(1,527.2$ ind.$\left./ \mathrm{m}^{2}\right)$ 。2 个年度均是植食者 $(\mathrm{Ph})$ 的栖息密度最高, 分别占 2 个年度总栖息密度的 $51.69 \%$ 和 $33.26 \%$, 即 2013-2014年度植食者 $(\mathrm{Ph})$ 栖息密度优势降低; 2 个 年度均是碎屑食者 $(\mathrm{D})$ 栖息密度最低, 分别占总栖 息密度的 $0.39 \%$ 和 $3.20 \%$ 。

\section{3 大型底栖动物功能群生物量组成}

2007-2008年度大型底栖动物平均生物量为 $80.67 \mathrm{~g} / \mathrm{m}^{2}$, 茫芏生境略低于海桑生境, 冬季明显高 于其他季节。茫芏和海桑生境均是植食者 $(\mathrm{Ph})$ 占优 势, 分别占总生物量的 $71.76 \%$ 和 $72.81 \%$ 。碎屑食者 (D)在两种生境中生物量很低, 占总生物量的百分 比均小于 $0.01 \%$ 。碎屑食者 $(\mathrm{D})$ 在夏季和春季没有被 采集到(图4A)。

2013-2014年度大型底栖动物平均生物量为 $72.43 \mathrm{~g} / \mathrm{m}^{2}$, 茫芏生境略高于海桑生境, 四个季节的 大型底栖动物生物量差幅较小, 最大差幅为 26.61 $\mathrm{g} / \mathrm{m}^{2}$ 。茫芏和海桑生境均以植食者 $(\mathrm{Ph})$ 的生物量最 高, 分别占总生物量的 $55.18 \%$ 和 $63.48 \%$ 。肉食者 $(\mathrm{C})$ 生物量在茫芏生境占总生物量的 $33.68 \%$ 。碎屑食者 (D)在两种生境中生物量很低, 分别占总生物量的 $0.14 \%$ 和 $0.46 \%$ 。四个季节均以植食者 $(\mathrm{Ph})$ 的生物量 最高, 在春季、夏季、秋季和冬季分别占总生物量
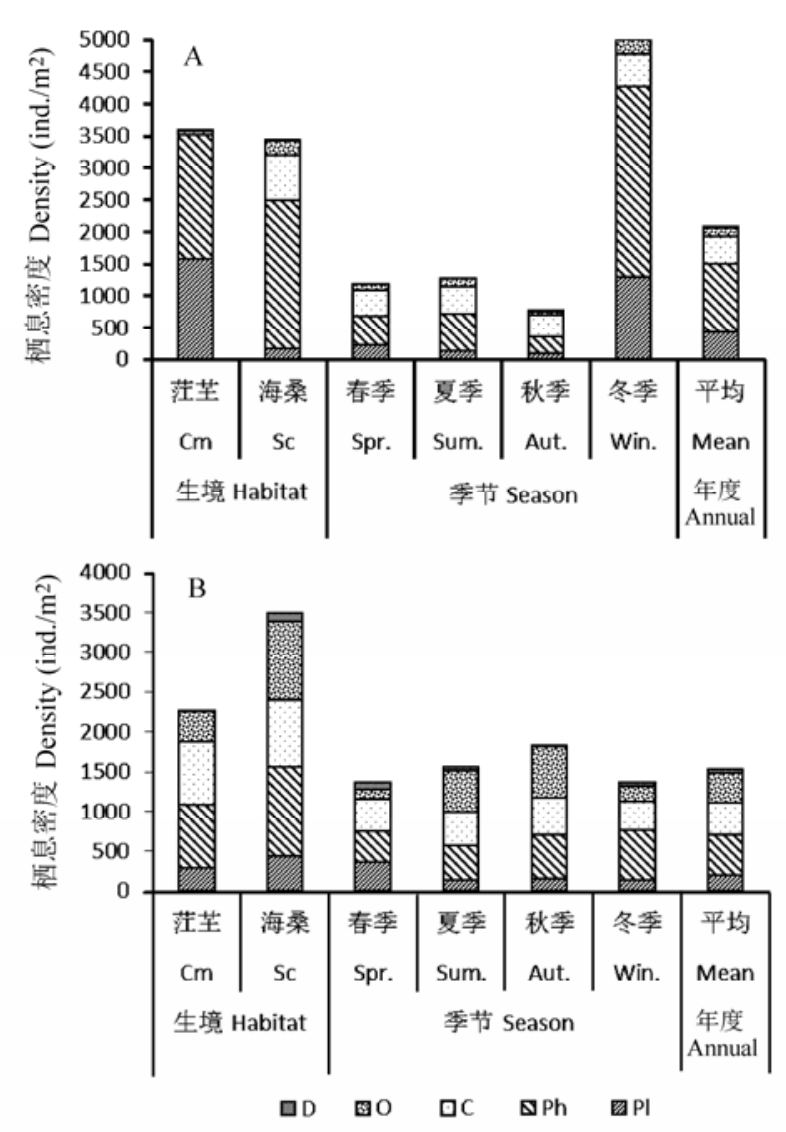

图3 2007-2008年度 $(A)$ 和 2013-2014年度 $(B)$ 大型底栖动物 功能群栖息密度组成。Cm: Cyperus malaccensis; Sc: Sonneratia caseolaris; PI: 浮游生物食者; Ph: 植食者; C: 肉食 者; O: 杂食者; D: 碎屑食者。

Fig. 3 Density composition of benthic macrofauna functional groups in 2007-2008 (A) and 2013-2014 (B). Cm: Cyperus malaccensis; Sc: Sonneratia caseolaris; Pl: Planktonphagous; $\mathrm{Ph}$ : Phytophagous; C: Carnivorous; O: Omnivorous; D: Detritivorous

的 $63.06 \% 、 55.90 \% 、 62.16 \%$ 和 $59.40 \%$ 。四个季度生 物量最低的均为碎屑食者 $(\mathrm{D})$, 其平均生物量只有 $0.37 \mathrm{~g} / \mathrm{m}^{2}$, 仅占年度总生物量的 $0.51 \%$ (图4B)。

2007-2008年度大型底栖动物生物量 $(80.67$ $\left.\mathrm{g} / \mathrm{m}^{2}\right)$ 高于2013-2014年度 $\left(72.43 \mathrm{~g} / \mathrm{m}^{2}\right)$, 差幅较小。 2 个年度均是植食者 $(\mathrm{Ph})$ 的生物量最高, 分别占 2 个 年度总生物量的 $72.31 \%$ 和 $60.20 \% ; 2$ 个年度均是碎 屑食者 $(\mathrm{D})$ 生物量最低, 分别占 2 个年度总生物量的 $0.01 \%$ 和 $0.51 \%$ 。

\section{4 大型底栖动物功能群多样性指数}

在2007-2008年度, 广州南沙十四涌潮间带各 功能群大型底栖动物Margalef种类丰富度指数 $(d)$ 结 果显示，除了杂食者 $(\mathrm{O})$ 外，均是茫芏生境高于海桑 

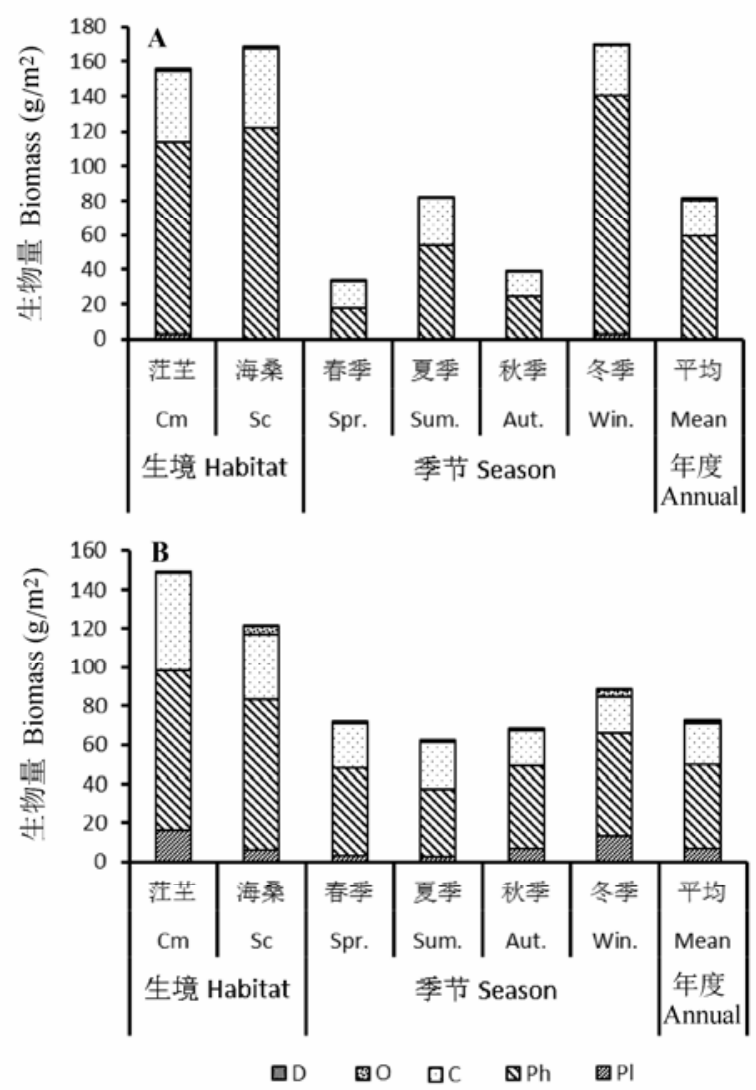

图4 2007-2008年度 $(A)$ 和 2013-2014年度 $(B)$ 大型底栖动物 功能群生物量组成。Cm: Cyperus malaccensis; Sc: Sonneratia caseolaris; $\mathrm{Pl}$ : 浮游生物食者; $\mathrm{Ph}$ : 植食者; $\mathrm{C}$ : 肉食 者; O: 杂食者; D: 碎屑食者。

Fig. 4 Biomass composition of benthic macrofauna functional groups in 2007-2008 (A) and 2013-2014 (B). Cm: Cyperus malaccensis; Sc: Sonneratia caseolaris; Pl: Planktonphagous; $\mathrm{Ph}$ : Phytophagous; C: Carnivorous; O: Omnivorous; D: Detritivorous

生境。分季节来看, 冬季各功能群大型底栖动物的 丰富度指数 $(d)$ 高于其他季节, 其中冬季肉食者 $(\mathrm{C})$ 最高, 达 0.99 。就全年来看, 丰富度指数 $(d)$ 最高的是 杂食者(0.99), 碎屑食者由于物种太少, 其丰富度指 数值小于 0.01 (表 1$)$ 。

各功能群大型底栖动物Pielou均匀度指数 $(J)$ 结 果显示, 茫芏生境均高于海桑生境, 其中茫芏生境 中杂食者 $(\mathrm{Ph})$ 最高 $(0.56)$, 海桑生境中植食者 $(\mathrm{Ph})$ 最 低(0.05)。分季节来看, 冬季各功能群大型底栖动物 的均匀度指数 $(J)$ 高于其他季节, 其中冬季杂食者 $(\mathrm{O})$ 最高, 达 0.69 , 夏季植食者 $(\mathrm{Ph})$ 最低, 只有 0.05 。 就全年来看, 均匀度指数 $(J)$ 最高的为杂食者 $(0.44)$, 最低为浮游生物食者 $(0.13)($ 表 1$)$ 。

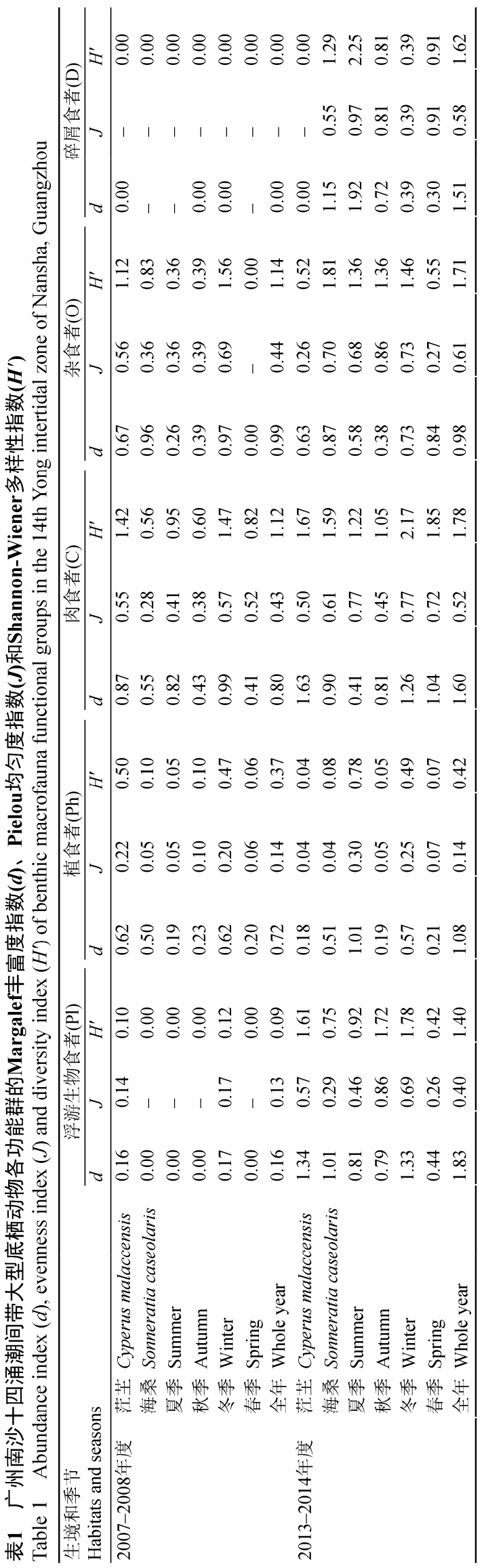


各功能群大型底栖动物Shannon-Wiener多样性 指数 $\left(H^{\prime}\right)$ 结果显示, 茫芏生境均高于海桑生境, 其 中茫芏生境中肉食者 $(\mathrm{C})$ 的Shannon-Wiener多样性 指数 $\left(H^{\prime}\right)$ 最高 $(1.42)$, 海桑生境中碎屑食者 $(\mathrm{D})$ 最低, 小于 0.01 。分季节来看, 冬季各功能群大型底栖动 物的Shannon-Wiener多样性指数 $\left(H^{\prime}\right)$ 高于其他季节, 其中冬季杂食者 $(\mathrm{O})$ 的多样性指数 $\left(H^{\prime}\right)$ 最高 $(1.56)$, 秋季碎屑食者 $(\mathrm{D})$ 最低, 小于 0.01 。从2007-2008年度 看, Shannon-Wiener多样性指数 $\left(H^{\prime}\right)$ 最高为杂食者 (C)(1.14), 最低为碎屑食者(D), 小于 0.01 (表1)。

在2013-2014年度, 广州南沙十四涌潮间带各 功能群大型底栖动物Margalef种类丰富度指数 $(d)$ 结 果显示, 茫芏生境肉食者 $(\mathrm{C})$ 的丰富度指数 $(d)$ 最高 (1.63), 植食者 $(\mathrm{Ph})$ 最低 $(0.18)$ 。分季节来看, 冬季各 功能群大型底栖动物的丰富度指数 $(d)$ 一般要高于 其他季节, 夏季碎屑食者 $(\mathrm{D})$ 的丰富度指数 $(d)$ 最高 (1.92), 秋季植食者 $(\mathrm{Ph})$ 最低(0.19)。就全年来看, 丰 富度指数 $(d)$ 最高的是浮游生物食者 $(1.83)$, 最低为 杂食者 $(0.98)$ (表 1$)$ 。

各功能群大型底栖动物Pielou均匀度指数 $(J)$ 结 果显示, 海桑生境杂食者 $(\mathrm{O})$ 的均匀度指数 $(J)$ 最高 $(0.70)$, 茫芏和海桑生境中植食者 $(\mathrm{Ph})$ 最低 $(0.04)$ 。分 季节来看, 冬季各功能群大型底栖动物的均匀度指 数 $(J)$ 一般要高于其他季节, 夏季碎屑食者 $(\mathrm{D})$ 的均 匀度指数 $(J)$ 最高 $(0.97)$, 秋季植食者 $(\mathrm{Ph})$ 最低 $(0.05)$, 这与丰富度指数 $(d)$ 结果保持一致。就全年来看, 均 匀度指数 $(J)$ 最高为杂食者 $(0.61)$, 最低为植食者 (0.14)(表1)。

各功能群大型底栖动物Shannon-Wiener多样性 指数 $\left(H^{\prime}\right)$ 结果显示, 海桑生境杂食者 $(\mathrm{O})$ 的多样性指 数最高(1.81), 茫芏生境中植食者最低(0.04), 结果 与均匀度指数 $(J)$ 相同。分季节来看, 冬季各功能群 大型底栖动物的多样性指数 $\left(H^{\prime}\right)$ 一般要高于其他季 节, 夏季碎屑食者(D)的多样性指数 $\left(H^{\prime}\right)$ 最高 $(2.25)$, 秋季植食者 $(\mathrm{Ph})$ 最低 $(0.05)$, 该结果亦与丰富度指数 $(d)$ 、均匀度指数 $(J)$ 保持一致。就全年来看, 多样性 指数 $\left(H^{\prime}\right)$ 最高为肉食者 $(\mathrm{C})(1.78)$, 最低为植食者 $(\mathrm{Ph})$ (0.42) (表1)。

\section{4 讨论}

\section{1 环境因子对群落结构和功能群组成的影响}

大型底栖动物群落组成和分布主要取决于自
然环境的性质, 如环境污染、水动力条件、盐度、 温度等(从建国, 1998; 周时强等, 2001)。2013-2014 年度与2007-2008年度分别采集到大型底栖动物36 种和26种, 与朱晓君和陆健健(2003)在长江口九段 沙潮间带获取的大型底栖动物种类数相当(38种), 但与辛俊宏等(2011)研究的胶州湾西北部潮滩湿地 (71种)、廖一波等(2013)调查的浙江西门岛(78种)相 差较大。这可能与广州南沙十四涌潮间带海水盐度 低有直接的关系。采样时测得2013年7月、10月和 2014年4月的平均海水盐度只有 0.4 , 而且均采集到 溪沙蚕(Namalycastis abiuma)、羽须鳃沙䖯(Dendronereis pinnaticirrus) 等低盐种以及一些淡水种如 扁卷螺(Gyraulus sp.)、河蚬(Corbicula fluminea), 而 辛俊宏等(2011)、李少文等(2013)、廖一波等(2013) 调查的区域海水盐度要高。

其次, 沉积物差异会在一定程度上影响大型底 栖动物物种多样性和功能群组成。从本文的研究结 果来看, 主要表现为: (1)底质的不同导致群落的物 种组成和优势种存在很大偏差。柔软底质的茫芏和 海桑生境以宽身闭口蟹和腺带刺沙䖯为优势种, 而 硬底质不适合爬行多毛类的生存, 其优势种是沼蚓 和腹足类。(2)不同类型的沉积物为大型底栖动物提 供不同的食物类型, 从而影响功能群的组成。

人为干扰对大型底栖动物群落结构也有一定 的影响。广州南沙十四涌潮间带位于洪奇沥水道下 游, 往来船只较多, 水面经常漂浮一层油膜, 对沿 岸植被和土壤造成污染, 这些人类活动导致的环境 污染, 使得 2 种生境中均有不少适应于高有机质环 境的种类(如小头虫、寡毛类)的分布。因此, 水体盐 度、沉积物特性和人为干扰等多种因素共同作用影 响着广州南沙十四涌潮间带大型底栖动物的群落 结构和功能群组成。

\section{2 不同生境类型导致功能群的差异}

在广州南沙十四涌潮间带两种生境中植食者 的栖息密度和生物量基本处于最高水平, 这一结果 与泉州湾蟳埔潮间带(李想等, 2014)的结果一致, 这 主要是由于广州南沙十四涌茫芏和海桑这两种生 境位于潮间带的中潮区, 且底质为泥沙。而在胶州 湾、莱州湾和浙江西门岛这些区域植食者的栖息密 度和生物量很低甚至没有, 原因主要是这些区域底 质多为软泥, 缺乏藻类生长所需的岩石岸和砾石滩 等硬相底质, 导致植食者功能群因为缺少食物而无 
法生存。

底栖动物功能群多样性是对环境梯度和生境 质量的综合反映(Engle \& Summers, 1999)。植被的 类型、覆盖度将直接影响营养源的分布和食物结构, 从而进一步影响底栖动物功能群的分布(Douglas \& Mitsch, 2003), 这在本文中得到充分反映。结果显示 茫芏生境中植食者的丰富度指数 $(d)$ 、均匀度指数 $(J)$ 、多样性指数 $\left(H^{\prime}\right)$ 均较低。这是由于取样地茫芏 平均高0.6-1.0 m, 植被郁闭度不高, 而且其生长在 海堤以及海堤前的光滩上, 受潮汐影响极大。而海 桑林内密具气生根, 能为大型底栖动物提供更多栖 息的场所。在2013-2014年度, 虽然植食者在茫芏生 境中有 5 种, 但个别物种栖息密度和生物量极高, 这导致了植食者的丰富度指数 $(d)$ 、均匀度指数 $(J)$ 、 多样性指数 $\left(H^{\prime}\right)$ 低于浮游生物食者、肉食者和杂食 者功能群。

此外, 通过对年际间两种共同生境(茫芏和海 桑)的大型底栖动物的功能群结构进行分析后发现, 2013-2014年度的各功能群的物种多样性要高于 $2007-2008$ 年度, 但是唯独植食者 $(\mathrm{Ph})$ 在栖息密度和 生物量方面出现较大程度的下降。黄丽等(2013)研究 发现老林的大型底栖动物的种类丰度和物种多样性 最高, 并不与红树林的发育呈负相关。广州南沙十四 涌茫芏和海桑林规模较小而且会受到洪奇沥水道潮 汐的影响, 这可能是导致这两种生境中大型底栖动 物各功能群的物种多样性出现增加的主要原因。同 时由于采样点位于洪奇沥水道的下游, 近年来油污 和河道淤积等生态环境问题越来越严重, 藻类无法 在这样的环境下生存, 导致一些植食者 $(\mathrm{Ph})$ 特别是 腹足类无法获得足够食物而数量急剧下降。

\section{3 不同功能群研究方法的比较}

在海洋生态系统中, 研究大型底栖动物功能多 样性的方法一般分为三种: 相对类群分析法、营养 群分析法和生物特征法(BTA), 其中前两种为已得 到普遍应用的传统方法。相对类群分析法是将各站 位大型底栖动物的相对生物量进行测定, 然后依据 相对生物量的差异性运用主成分分析法进行线性 分类, 此方法依据的是大型底栖动物生物量的差异 而非形态学上的不同, 从而大大减少了工作量。营 养群分析法是依据研究海域内大型底栖动物的营 养摄食方式的差别将其划分为沉积食者、滤食者、
食碎屑者和肉食者, 然后运用主成分分析法将各站 位营养群类型进行线性分类。该方法经袁兴中等 (2002)、朱晓君和陆健健(2003)的改进和发展而成为 国内研究海洋底栖动物功能群的一种普遍方法。生 物特征法在 2003 年被Bremner等人首次应用于海洋 底栖生态系统中, 而且与相对类群分析法和营养群 分析法做了详细的比较, 然后又经改进(Bremner et al, 2006; Paganelli et al, 2012)而更加完善。该方法选 择大型底栖动物在生活史、形态学和习性方面的多 项生物特征，在之下又分为次一级的类别，然后根 据各个物种的差异而赋予相应的值，最终运用模糊 一致性分析法(fuzzy correspondence analysis, FCA) 和协同惯性分析(coinertia analysis, CoI)等特征分析 方法来对底栖动物群落功能多样性进行分析。

生物特征法有诸多优势: (1)它采用了多元分类 方法来描述生物特征模型, 由Bremner等(2003)最初 所采用的9种到后来的13种再到Paganelli等(2012)的 11种。(2) 它在进行底栖动物群落功能多样性分析时 不仅将物种的相对生物量纳入其中, 还包括它们的 生态学特征信息。(3)它使用的模糊一致性分析和协 同惯性分析方法较之主成分分析法更能直观地反 映功能类群组成及其差异性。但生物特征法的漏洞 和缺陷也不可忽视。首先, 底栖动物生物特征尚缺 乏一个完整的数据库能包含所有的物种, 要建立这 样一个数据库需要耗费大量的时间和资源, 再加上 底栖动物种类信息又在不断地变化, 更给数据库的 更新和完善带来巨大的工作量。其次, 被用于评价 底栖动物群落功能多样性的生物特征数还未完全 确定, 如果所选择的生物特征数太多需要耗费大量 的资源和时间, 太少将难以完整地描述底栖动物类 群的功能差异性, 甚至有可能产生误导性的结果。 最后, 已有的研究仅限于北欧国家和地中海地区的 潮下带区域(Bremner et al, 2006; Paganelli et al, 2012; Van der Linde et al, 2012), 但这种方法能不能 用于本研究所在的潮间带区域尚未可知。

相比于生物特征法, 本研究所采用的由营养群 分析法所发展而来的功能群方法则要成熟得多而 且在操作上更简便, 而且国内已有多位研究者将功 能群方法广泛应用于各河口和潮间带区域。基于以 上各方面考虑, 本研究采用更适合的功能群方法来 进行研究。 


\section{参考文献}

Bremner J, Rogers SI, Frid CLJ (2003) Assessing functional diversity in marine benthic systems: a comparison of approaches. Marine Ecology Progress Series, 254, 11-25.

Bremner J, Rogers SI, Frid CLJ (2006) Methods for describing ecological functioning of marine benthic assemblages using biological traits analysis (BTA). Ecological Indicators, 6, 609-622.

Cai LZ (2015) Zoobenthic Ecology in Shenzhen Bay. Xiamen University Press, Xiamen. (in Chinese) [蔡立哲 (2015) 深 圳湾底栖动物生态学. 厦门大学出版社, 厦门.]

Chang H, Chen RX, Su J, Xiao JJ, Liao BW, Zhang GP (2007) Habitat and bird diversities of mangroves in Xinken, Guangzhou City. Sichuan Journal of Zoology, 26, 561-565. (in Chinese with English abstract) [常弘, 陈仁先, 粟娟, 肖嘉杰, 廖宝文, 张国萍 (2007) 广州新垦红树林湿地鸟 类多样性与生境分析. 四川动物, 26, 561-565.]

Cong JG (1998) The common invertebrate community and its diversity in the beach of intertidal zone, Yantai. Acta Ecologica Sinica, 18, 56-62. (in Chinese with English abstract) [丛建国 (1998) 烟台潮间带底栖无脊椎动物群落 和多样性研究. 生态学报, 18, 56-62.]

Douglas JS, Mitsch WJ (2003) A model of macroinvertebrate trophic structure and oxygen demand in freshwater wetlands. Ecological Modelling, 161, 183-194.

Engle VD, Summers JK (1999) Latitudinal gradients in benthic community composition in western Atlantic estuaries. Journal of Biogeography, 26, 1007-1023.

Ge BM, Bao YX, Cheng HY, Li HH, Hu ZY (2008) The trophic functional groups and trophic levels of the macrobenthic community at the east tidal flat of Lingkun Island. Acta Ecologica Sinica, 28, 4796-4804. (in Chinese with English abstract) [葛宝明, 鲍毅新, 程宏毅, 李欢欢, 胡知渊 (2008) 灵昆岛东滩潮间带大型底栖动物功能群及营养等 级构成. 生态学报, 28, 4796-4804.]

Huang L, Chen SB, Qiu JB, Ding WY, Zheng CF, Wu JG, Zhou ZM, Wang N (2013) Influences of artificial Kandelia obovata mangrove forest rehabilitation on the macrobenthos in Ximen Island. Acta Ecologica Sinica, 33, 3138-3147. (in Chinese with English abstract) [黄丽, 陈少波, 仇建标, 丁 文勇, 郑春芳, 伍锦姑, 周志明, 王宁 (2013) 西门岛人 工秋茄林恢复对大型底栖生物的影响. 生态学报, 33, 3138-3147.]

Huang RJ, Cai LZ, Ye JQ, Zhou XP, Liu S, Xu P, Peng X, Cao $J$ (2010) Macrofaunal community at three habitats in the 14th Yong intertidal zone of Nansha, Guangzhou. Chinese Journal of Ecology, 29, 1187-1192. (in Chinese with English abstract) [黄睿婧, 蔡立哲, 叶洁琼, 周细平, 刘莎, 许鹏, 彭欣, 曹婧 (2010) 广州南沙十四涌潮间带三种生 境的大型底栖动物群落比较. 生态学杂志, 29 , 1187-1192.]

Li HH, Bao YX, Hu ZY, Ge BM (2007) Seasonal dynamics of macrobenthic functional groups and trophic levels in the bridge construction zone at the South Bank of Hangzhou Bay, China. Acta Zoologica Sinica, 53, 1011-1023. (in Chinese with English abstract) [李欢欢, 鲍毅新, 胡知渊, 葛宝明 (2007) 杭州湾南岸大桥建设区域潮间带大型底 栖动物功能群及营养等级的季节动态. 动物学报, 53, 1011-1023.]

Li SW, Liu YJ, Li F, Zhang Y, Xu ZF, Lü ZB, Wang TT, Zhang AB (2013) Macrobenthic functional groups in Laizhou Bay, East China. Chinese Journal of Ecology, 32, 380-388. (in Chinese with English abstract) [李少文, 刘元 进, 李凡, 张莹, 徐宗法, 吕振波, 王田田, 张爱波 (2013) 莱州湾大型底栖动物功能群现状. 生态学杂志, 32, 380-388.]

Li X, Cai LZ, Zhuo Y, Guo T, Rao YY, Yan LL, Fu SJ, Chen XW (2014) Functional groups of macrofauna in Xunpu intertidal zone, Quanzhou Bay. Marine Science Bulletin, 33, 497-504. (in Chinese with English abstract) [李想, 蔡立哲, 卓异, 郭涛, 饶义勇, 颜露露, 傅素晶, 陈昕鞾 (2014) 泉州湾蟳埔潮间带大型底栖动物功能群研究. 海洋通报, 33, 497-504.]

Liao BW, Wu M, Su J, Guan W, Li M, Chen YJ (2013) Environment and Biodiversity of Nansha Wetland. Guangdong Science and Technology Press, Guangzhou. (in Chinese) [廖 宝文, 吴敏, 粟娟, 管伟, 李玫, 陈玉军 (2013) 南沙湿 地环境与生物多样性. 广东科技出版社, 广州.]

Liao YB, Shou L, Zeng JN, Gao AG, Tang YB, Yan XJ, Chen QZ (2013) Functional groups of marine macrobenthos in relation to environmental factors around the Ximen Island National Marine Special Reserve, Zhejiang. Biodiversity Science, 21, 3-10. (in Chinese with English abstract) [廖一波, 寿鹿, 曾江宁, 高爱根, 汤雁滨, 严小军, 陈全震 (2013) 浙江西门岛海洋特别保护区大型底栖动物功能群特征及 其与环境的关系. 生物多样性, 21, 3-10.]

Liu S, Cai LZ, Xu P, Peng X, Cao J, Fu SJ (2011) Macrofaunal community at three botanic habitats in the 19th Yong of Nansha, Guangzhou. Journal of Quanzhou Normal University, 29(2), 1-7. (in Chinese with English abstract) [刘莎, 蔡立哲, 许鹏, 彭欣, 曹婧, 傅素晶 (2011) 广州南沙十 九涌三种植物生境的大型底栖动物群落. 泉州师范学院 学报, 29(2), 1-7.]

Ma KP (1994) The measurement of community diversity. In: Principles and Methodologies of Biodiversity Studies (eds Qian YQ, Ma KP), pp. 141-165. Chinese Science and Technology Press, Beijing. (in Chinese) [马克平 (1994) 生 物群落多样性的测度方法. 见: 生物多样性研究的原理 与方法 (钱迎倩, 马克平主编), 141-165. 中国科学技术 出版社, 北京.]

Paganelli D, Marchini A, Occhipinti-Ambrogi A (2012) Functional structure of marine benthic assemblages using Biological Traits Analysis (BTA): a study along the Emilia-Romagna coastline (Italy, North-West Adriatic Sea). Estuarine, Coastal and Shelf Science, 96, 245-256.

Van der Linde P, Patricio J, Marchini A, Cid N, Neto JM, 
Marques JC (2012) A biological trait approach to assess the functional composition of subtidal benthic communities in an estuarine ecosystem. Ecological Indicators, 20, 121-133.

Wei DZ, Xiang CY, Bao YX, Li LF, Zhang SS (2012) Effect of mangrove planting on macrobenthic community structure and functional group. Journal of Zhejiang Normal University, 35, 195-202. (in Chinese with English abstract) [魏德 重, 项长友, 鲍毅新, 李良峰, 章书声 (2012) 红树林种 植对大型底栖动物群落结构及功能群的影响. 浙江师范 大学学报, 35, 195-202.]

Xin JH, Ren YP, Xu BD, Zhang CL, Xue Y, Ji YP (2011) Macrozoobenthos functional groups in intertidal flat of northwest Jiaozhou Bay. Chinese Journal of Applied Ecology, 22, 1885-1892. (in Chinese with English abstract) [辛 俊宏, 任一平, 徐宾铎, 张崇良, 薛荣, 纪毓鹏 (2011) 胶州湾西北部潮滩湿地大型底栖动物功能群. 应用生态 学报, 22, 1885-1892.]
Yuan XZ, Lu JJ, Liu H (2002) Distribution pattern and variation in the functional groups of zoobenthos in the Changjiang Estuary. Acta Ecologica Sinica, 22, 2054-2062. (in Chinese with English abstract) [袁兴中, 陆健健, 刘红 (2002) 长江口底栖动物功能群分布格局及其变化. 生态 学报, 22, 2054-2062.]

Zhou SQ, Guo F, Wu LS, Li RG (2001) Benthic community ecology in the island intertidal zone of Fujian. Acta Oceanologica Sinica, 23, 104-109. (in Chinese with English abstract) [周时强, 郭丰, 吴荔生, 李荣冠 (2001) 福建海 岛潮间带底栖生物群落生态的研究. 海洋学报, 23 , 104-109.]

Zhu XJ, Lu JJ (2003) Functional groups of zoobenthos in the intertidal zone of Jiuduansha, the Yangtze River Estuary. Zoological Research, 24, 355-361. (in Chinese with English abstract) [朱晓君，陆健健 (2003) 长江口九段沙潮间带 底栖动物的功能群. 动物学研究, 24, 355-361.]

(责任编委: 李新正 责任编辑: 间文杰)

附录1 广州南沙十四涌潮间带大型底栖动物功能群

Appendix 1 Functional groups of benthic macrofauna in the 14th Yong intertidal zone of Nansha, Guangzhou http://www.biodiversity-science.net/fileup/PDF/2015270-1.pdf 
颜露露, 蔡立哲, 陈昕鞾, 李国强, 李文君, 曾佳丽, 饶义勇. 广州南沙十四涌潮间带大型底栖动物的功能群. 生物多样性, 2016, 24 (7): 802-810

http://www.biodiversity-science.net/CN/10.17520/biods.2015270

附录1 广州南沙十四涌潮间带大型底栖动物功能群

Appendix 1 Functional groups of benthic macrofauna in the 14th Yong intertidal zone of Nansha, Guangzhou

\begin{tabular}{|c|c|c|c|c|}
\hline 类群 & 中文名 & 功能群 & 2007-2008年 & 2013-2014年 \\
\hline 刺胞动物 & 纵条矶海葵 Haliplanella luciae & $\mathrm{O}$ & & + \\
\hline \multirow[t]{2}{*}{ 纽形动物 } & 脑纽虫 Cerebratulus sp. & C & + & + \\
\hline & 东方原细首纽虫 Cephalothrix orientalis & $\mathrm{C}$ & & + \\
\hline \multirow[t]{16}{*}{ 多毛类 } & 小头虫 Capitella capitata & $\mathrm{D}$ & & + \\
\hline & 刚鳃虫 Chaetozone setosa & $\mathrm{D}$ & & + \\
\hline & 羽须鳃沙蚕 Dendronereis pinnaticirrus & C & & + \\
\hline & 三角洲双须虫 Eteone delta & $\mathrm{C}$ & + & \\
\hline & 加州中蚂虫 Mediomastus californiensis & $\mathrm{D}$ & + & \\
\hline & 溪沙蚕 Namalycastis abiuma & $\mathrm{C}$ & + & + \\
\hline & 腺带刺沙蚕 Neanthes glandicincta & $\mathrm{C}$ & & + \\
\hline & 寡鰓齿吻沙蚕 Nephtys oligobranchia & C & + & + \\
\hline & 背蚓虫 Notomastus latericeus & $\mathrm{D}$ & & + \\
\hline & 拟特须虫 Paralacydonia paradoxa & $\mathrm{C}$ & & + \\
\hline & 难定才女虫 Polydora pilikia & C & + & + \\
\hline & 刺缨虫 Potamilla sp. & $\mathrm{Pl}$ & + & + \\
\hline & 稚齿虫 Prionospio sp. & $\mathrm{O}$ & + & \\
\hline & 尖雉虫 Scoloplos sp. & $\mathrm{D}$ & & + \\
\hline & 独毛虫 Tharyx sp. & $\mathrm{D}$ & & + \\
\hline & 病吻沙蚕 Tylorrhynchus heterochaetus & $\mathrm{C}$ & + & + \\
\hline 寡毛类 & 沼蚓 Limnodriloides sp. & $\mathrm{O}$ & + & + \\
\hline \multirow[t]{4}{*}{ 腹足类 } & 短拟沼螺 Assiminea brevicula & $\mathrm{Ph}$ & + & \\
\hline & 扁卷螺 Gyraulus sp. & $\mathrm{Ph}$ & & + \\
\hline & 斜肋齿蜷 Sermyla riqueti & $\mathrm{Ph}$ & + & \\
\hline & 光滑狭口螺 Stenothyra glabar & $\mathrm{Ph}$ & + & \\
\hline \multirow[t]{9}{*}{ 双壳类 } & 河蚬 Corbicula fluminea & $\mathrm{Pl}$ & + & + \\
\hline & 小刀蛏 Cultellus attenuatus & $\mathrm{Pl}$ & + & + \\
\hline & 尖刀蛏 Cultellus scalprum & & & + \\
\hline & 红树蚬 Gelonia coaxans & $\mathrm{Pl}$ & & + \\
\hline & 丽文蛤 Meretrix lusoria & $\mathrm{Pl}$ & + & \\
\hline & 彩虹明樱蛤 Moerella iridescens & $\mathrm{Pl}$ & & + \\
\hline & 凸壳肌蛤 Musculus senhousia & $\mathrm{Pl}$ & & + \\
\hline & 光滑河蓝蛤 Potamocorbula laevis & $\mathrm{Pl}$ & & + \\
\hline & 缢蛏 Sinonovacula constricta & $\mathrm{Pl}$ & & + \\
\hline \multirow[t]{12}{*}{ 甲壳类 } & 沙钩虾 Byblis sp. & $\mathrm{O}$ & + & \\
\hline & 无齿螳臂相手蟹 Chiromantes dehaani & $\mathrm{Ph}$ & & + \\
\hline & 近似拟棒鞭水䖝 Cleantiella isopus & $\mathrm{O}$ & + & + \\
\hline & 宽身闭口蟹 Cleistostoma dilatatum & $\mathrm{Ph}$ & & + \\
\hline & 蜾贏蜚 Corophium sp. & $\mathrm{Pl}$ & + & + \\
\hline & 长足圆方蟹 Cyclograpsus longipes & $\mathrm{Ph}$ & & + \\
\hline & 平掌拟钩虾 Gammaropsis laevipalmata & $\mathrm{O}$ & + & + \\
\hline & 泥蟹 Ilyoplax sp. & $\mathrm{Ph}$ & + & \\
\hline & 海蟑螂 Ligia oceanica & $\mathrm{O}$ & & + \\
\hline & 太平大眼蟹 Macrophthalmus pacificus & $\mathrm{Ph}$ & + & \\
\hline & 四齿大额蟹 Metopograpsus quadridentatus & $\mathrm{O}$ & + & \\
\hline & 字纹弓蟹 Varuna litterata & $\mathrm{Pl}$ & & + \\
\hline \multirow[t]{2}{*}{ 昆虫类 } & 致倦库蚊 Culex fatigans & $\mathrm{O}$ & + & \\
\hline & 摇蚊幼虫 Chironomus spp. & $\mathrm{O}$ & + & + \\
\hline 底栖鱼类 & 弹涂鱼 Periophthalmus cantonensis & $\mathrm{O}$ & + & + \\
\hline
\end{tabular}

$\mathrm{Pl}:$ 浮游生物食者; Ph: 植食者; C: 肉食者; O: 杂食者; D: 碎屑食者。“+”表示在该年度发现此动物。 